\title{
Surveillance \& Society \\ Police Bodycams as Equiveillance Tools?: Reflections on the Debate in the Netherlands
} Dialogue

\section{Lotte Houwing}

Bits of Freedom, The Netherlands

rozemetglitters@systemausfall.org

\author{
Gerard Jan Ritsema van Eck
}

University of Groningen, The Netherlands

g.j.ritsema.van.eck@step-rug.nl

\begin{abstract}
In the United States of America, police body-worn cameras (bodycams) were introduced to protect civilians against violence by law enforcement authorities. In the Netherlands, however, the same technology has been introduced to record and discipline the behavior of the growing number of citizens using their smartphone cameras to film the (mis)conduct of police. In answer to these citizens sousveilling the police and publishing their images on social media, the bodycam was introduced as an objective referee that also includes the perspective of the police officer. According to this view, the bodycam is a tool of equiveillance: a situation with a diversity of perspectives in which surveillance and sousveillance are in balance (Mann 2005). Various factors, however, hamper the equiveillant usage of bodycams in the Netherlands. Firstly, the attachment of the bodycam to the uniform of the officer leads to an imbalanced representation of perspectives. The police perspective is emphasized by the footage that is literally taken from their perspective, in which others are filmed slightly from below, making them look bigger and more overwhelming. Also, the police officers' movements create shaky footage with deceptive intensity that invokes the image of a hectic situation that calls for police action. Secondly, it is the officer who decides when to wear a camera and when to start and stop recording. This leaves the potential to not record any misconduct. Thirdly, access to the recorded images, whilst in theory open to police and citizens alike, is in practice exclusively for the police. Within the current regulatory framework, bodycams are thus not neutral reporters of interactions between civilians and the police. We will end our contribution to this Dialogue section with suggestions for the improvement of those rules and reflect on the question of whether bodycams can ever be objective referees.
\end{abstract}

\section{Introduction}

In the United States of America, police body-worn cameras (bodycams) were introduced and promoted as a means of protecting civilians against violence by law enforcement authorities (e.g., ACLU n.d.). In the Netherlands, however, the same technology has been introduced for a very different, and quite opposite, reason: to record and discipline the behaviour of people interacting with the police. An important component of this behaviour is the sousveillant practices made possible by smartphone cameras that allow citizens to film interactions with law enforcement authorities (Mann, Nolan, and Wellman 2003). According to the Dutch police, such sousveillant imagery cannot show the whole story as it inevitably excludes the perspective of the police officer. The introduction of the bodycam would thus provide an answer to this by creating an "equal playing field" (Raat 2016; our translation). In our contribution, we will reflect on these arguments and the central role that sousveillance has played and continues to play in them. We conclude that although the police present the bodycam as just another neutral observer, the perspective of these cameras is inherently skewed. Currently, regulation to offset this skew is utterly lacking.

\section{Bodycams and Violence Towards the Police}

In the last decade, violence against emergency service personnel (including police officers but also EMT

Houwing, Lotte, and Gerard Ritsema van Eck. 2020. Police Bodycams as Equiveillance Tools?: Reflections on the Debate in the Netherlands. Surveillance \& Society 18(2): 284-287.

https://ojs.library.queensu.ca/index.php/surveillance-and-society/index | ISSN: 1477-7487

(C) The author(s), 2020 | Licensed to the Surveillance Studies Network under a Creative Commons

Attribution Non-Commercial No Derivatives license 
and fire department staff) has become a hotly debated topic in the Netherlands. As institutional trust in the Netherlands is generally high, many saw this development as unacceptable. Thus, in response, politicians demanded new methods through which to combat this increase in violence such as, inter alia, tough new sentencing guidelines. In this context, bodycams were presented as a way to de-escalate potentially violent encounters and gather evidence if necessary. A recent evaluation of the effectiveness of this by Sander Flight (2019) showed mixed evidence in this regard. ${ }^{1}$ In the areas where bodycams were introduced, violence was reduced and the feeling of safety of the police officers who were wearing the bodycams increased. According to Flight, however, it is hard to say whether the bodycams prevented citizens from being aggressive towards police officers or police officers acted more professionally and thus received a more respectful response. In this regard, it is notable that citizens often do not see the bodycam, and that, even when the camera is detected, it is difficult to see whether it is recording. Consequently, the citizen depends on the honesty and initiative of the police officer to know if a situation is being captured. As a tool to gather evidence, the results were decidedly disappointing: not a single recording was used as evidence in a criminal proceeding (Flight 2019: 56-57).

\section{The Bodycam as a Tool of Equiveillance}

The rise of sousveillant practices is the second major reason behind the introduction of bodycams in the Netherlands. Citizens use their smartphone cameras to film the police, including when misconduct is taking place, and publish these images on social media. There are several examples of such civilian-made images causing angry protests and negatively influencing the public opinion of the police. Recently, this includes the deadly strangulation of Mitch Henriquez (Omroep West 2017), and the case of a thirteen-year-old black arrestee who was cuffed to the motorcycle of an officer and made to jog alongside it the entire way to the police station (Almere Nieuws 2017). Both resulted in powerful images of police officers seemingly abusing their power. According to the police, however, such images cannot tell the whole story as they exclude the perspective of the police officer or miss the inducement behind their actions. According to Theo van der Plas, who is responsible for the introduction of bodycams at the Dutch national police, police bodycams were introduced with the express purpose of providing this perspective (qtd. in Andringa 2019). According to this view, the bodycam is a tool of equiveillance (Mann 2005).

Mann (2005) describes equiveillance as a situation with a diversity of perspectives in which surveillance and sousveillance are in balance. There are indeed a few aspects of Dutch police bodycams that might make them function as tools of equiveillance: Firstly, the Dutch national police wanted to introduce them in order to have imagery covering a larger timespan, for the purpose of complementing the often short videos that are shared on social media (e.g., Almere Nieuws 2017). Secondly, the police present themselves as a party with authority, and thus its imagery as neutral and trustworthy. Finally, any images recorded with a bodycam are (theoretically) available to the citizen as well as to the police. This makes it possible to use police bodycam footage in order to hold the wearer to account. However, various factors stand in the way of the proper functioning of the bodycam as a neutral observer and a tool of equiveillance.

First, the attachment of cameras to the bodies of police officers leads to an overrepresentation of the way that the police officers experience a situation (Brucato 2015: 466-69). This imbalance was clearly visible in the imagery produced with the bodycams of the police officers that shot Arlon Sterling in the US in 2016. This imagery gives a hectic physical impression, sometimes called "deceptive intensity," because of the jerkily moving images, the police screaming "Don't fucking move!" and "Get on the ground!," and the heavy breathing of the police officers. However, the same incident was filmed by a wall-mounted security camera. From this video it became clear that Sterling was not aggressive at all and that the shaky images were created because the police attacked him (NOS 2018). ${ }^{2}$ The fact that the imagery is taken from the

\footnotetext{
${ }^{1}$ There have been several pilots on the introduction of bodycams in the Netherlands. Researcher Sander Flight focused on the pilot in Amsterdam.

2 More examples of deceptive intensity can be found in the video at: https://media.ccc.de/v/SHA2017-27hands_up_don_t_shoot_unless_with_a bodycam\#t=2134, e.g., at 34:00 and at 35:58.
} 
physical perspective of the police officer has another effect: you only see the face of the citizen and not that of the police officers. The viewer experiences the situation from the perspective of the police, which creates an emotional connection (McKay and Lee 2019). Finally, as bodycams are usually placed on the chest, others are filmed from slightly below. This makes them look bigger and more overwhelming than if the bodycam was placed for example on the head or shoulder of the police officer.

Second, the manner in which body-worn camera images are created further hampers the equiveillant use of bodycams. In the Netherlands (but also in Belgium; e.g., van den Panhuyzen 2019) there is currently no regulation for when a police bodycam should be recording, leaving this decision up to the wearer-if the officer even decides to wear a camera, as this is currently also voluntary. This results in a power imbalance as an officer could, for instance, turn on the bodycam after insulting a person and just film their reaction. Furthermore, what is viewed by the camera is decided by the police officers since the camera is attached to their bodies. By simply turning the other way or covering the lens, events and persons could be deliberately placed within or outside of the recorded area (see also Mann's contribution to this Surveillance \& Society dialogue section).

Third, and just as important, is how images from bodycams can be used and for what purposes; power over the images means power over the story. The same imbalance that exists in relation to the recording of images also exists in relation to the storage of the images beyond a standard four-week period. Whether or not this happens is, again, left to the discretion of the police. Although any recorded citizen has a legal right to access bodycam images, as was pointed out above, it is not always clear for citizens whether there even is footage of their encounter with the police. If there is, the procedure for requesting the imagery is obscure, making it difficult to file a complaint. Thus, the legal right to access may be nigh impossible to exercise in practice. Finally, there exists an inherent tension with the right to privacy in this regard. While footage needs to be kept available in order for it to be used in a complaint procedure, it should not be retained any longer than strictly necessary in order to protect the right to privacy of all data subjects (including bystanders) filmed.

Looking again at Mann's concept of equiveillance, important aspects include ensuring documentation from a diversity of perspectives and finding the balance between surveillance and sousveillance. Both aspects put emphasis on an equal distribution of power, control, and representation. The usage of bodycams by the Dutch police fails to meet the basic demands of this concept. It does not provide for a diversity of perspectives since there is a clear and inherent overrepresentation of the perspective of the police officers wearing the bodycams on their bodies. Also, control over the creation of the images lies solely with the police since it is the police who decide whether to record an event and when to record. Finally, the ability to use the created images is not shared equally, since it is not always clear for citizens whether there are images, and, if so, how they can access them and what value is attached to the images in what procedures. Since none of the aspects are equally distributed, the deployment of the bodycam in the Netherlands cannot be qualified as a means of equiveillance.

Note that the police discretion to (not) record interactions also has implications for practices which involve creating "statistics from below" (Thompson 2018), such as those described in Harju's contribution on copwatching in Germany to this Dialogue section. However, for footage to be useful for such a purpose it needs to exist. Situations which do not seem noteworthy to the police officer involved will remain undocumented, as there seems to be no reason to turn on the camera. This means that any instances in which implicit biases influenced police behaviour, leading to, for example, racial profiling, have a very small chance of being recorded. If footage does not exist, it cannot be accessed and used to challenge the police on any implicit biases, nor in individual cases or to create statistics from below.

\section{Conclusion: It's Not about Bodycams, It's about Regulating Bodycams}

Worldwide, smartphones and social media are being used to record the conduct of police officers, functioning as a powerful form of sousveillance. In the Netherlands, the police reacted to these practices by introducing body-worn cameras under the guise of an attempt at equiveillance. However, nowadays cameras 
can be found all throughout public and private spaces - attached to streetlights, on the bodies of police officers, and in the pockets of most people. Simply adding more cameras to this mix does not automatically create a surveillance/sousveillance equilibrium.

If bodycams are truly to function as "objective referees," then the Dutch police must consciously assign this role to them (Flight 2019). The police need to focus their attention not just on the technology itself, but also on the societal context and the technology users (see Wennekes 2019). The question remains as to whether the bodycam is suitable to function as an "objective referee" and achieve the stated goal of equiveillance. However, when bodycams are introduced, we suggest that comprehensive regulation is needed for at least the following three areas: first, the placement of the camera on the body of the officers must be regulated; second, we must regulate which situations will be filmed and when the camera should be on, rather than leaving this decision to individual police officers; and, most importantly, the citizens' access to recorded images must be made equal to that of the police by way of a simple procedure. If swiftly implemented, such regulations would form a welcome first step towards actual equiveillance.

\section{Acknowledgments}

Lotte Houwing (rozemetglitters@systemausfall.org) is an expert in digital surveillance and works as a policy advisor and researcher at Bits of Freedom, the primary Dutch digital rights NGO. She wrote this piece in a personal capacity. Gerard Jan Ritsema van Eck (g.j.ritsema.van.eck@step-rug.nl) researches privacy in public space at the University of Groningen, the Netherlands. The authors thank Lauren Elrick for her careful language check.

\section{References}

ACLU. n.d. Police Body Cameras. American Civil Liberties Union. https://www.aclu.org/issues/privacy-technology/surveillancetechnologies/police-body-cameras [accessed November 25, 2019].

Almere Nieuws. 2017. Motoragent laat 13-jarige jongen geboeid mee rennen in Almere. Almere Nieuws, video, December 21. https://www.youtube.com/watch?v=aMENFw4CtZ8. [accessed November 25, 2019].

Andringa, Remco. 2019. Politie moet bodycams verplichten, nu te vrijblijvend. NOS, April 24. https://nos.n1/1/2281828 [accessed November 25, 2019].

Brucato, Ben. 2015. Policing Made Visible: Mobile Technologies and the Importance of Point of View. Surveillance \& Society 13 (3/4): 455-73.

Flight, Sander. 2019. Evaluatie Pilot Bodycams Politie Eenheid Amsterdam 2017-2018. Politie en Wetenschap. https://www.politieenwetenschap.nl/cache/files/5d8e04f882382PW93A.pdf [accessed September 27, 2019].

McKay, Carolyn, and Murray Lee. 2019. Body-Worn Images: Point-of-View and the New Aesthetics of Policing. Crime, Media, Culture 00 (0): 1-20.

Mann, Steve. 2005. Equiveillance: The Equilibrium between Sur-Veillance and Sous-Veillance. Paper presented at the ACM (Association of Computing Machinery) CFP (Computers, Freedom, and Privacy), Seattle, May 12.

Mann, Steve, Jason Nolan, and Barry Wellman. 2003. Sousveillance: Inventing and Using Wearable Computing Devices for Data Collection in Surveillance Environments. Surveillance \& Society 1 (3): 331-55.

NOS. 2018. BODYCAM: Agent ontslagen na dood zwarte man." NOS, video, March 31. https://www.youtube.com/watch?v=Oiswx1h2VF4 [accessed November 28, 2019].

Omroep West. 2017. Beelden arrestatie Mitch Henriquez in Haagse Zuiderpark. Omroep West, video, December 21. https://www.youtube.com/watch?v=MC68xOg1vJQ [accessed November 25, 2019].

Raat, Herbert. 2016. Pilot bodycams bij Team Handhavlng Openbare Ruimte. Gemeente Amstelveen, 16 November. https://freedominc.nl/files/20161116-brief-bw-re-pilot-bodycams.pdf [accessed January 7, 2020].

Thompson, Vanessa E. 2018. "There is no justice, there is just us!” Ansätze zu einer postkolonial-feministischen Kritik der Polizei am Beispiel von Racial Profiling. In Kritik der Polizei, edited by Daniel Loick, 197-219. Frankfurt, DE: Campus Verlag.

Van den Panhuyzen, Kevin. 2019. Bodycams voor Brusselse politie: 'Vergroot kloof met burger.' Bruzz, 23 November. https:/www.bruzz.be/samenleving/bodycams-voor-brusselse-politie-vergroot-kloof-met-burger-2019-11-23 [accessed November 25, 2019].

Wennekes, Laura. 2019. Bodycams voor boa's: "Eerst denken, dan doen." Gemeente, November 17. https:/www.gemeente.nu/veiligheid/boa/bodycams-voor-boas-eerst-denken-dan-doen/ [accessed November 25, 2019]. 